\title{
Aspek Kognitif Dan Psikososial pada Anak Dengan Palsi Serebral
}

\author{
Oka Lely $A A^{*}$, Soetjiningsib**
}

Palsi serebral merupakan kelainan motorik yang banyak dijumpai pada anak. Kelainan ini disebabkan oleh kerusakan otak yang menetap, tidak progresif, terjadi pada usia dini dan merintangi perkembangan otak normal. Pusat motorik di otak terletak di bagian posterior dari lobus frontalis dan di sebelah anteriornya terletak pusat menyimpan ingatan baru. Lobus temporal, parietal dan oksipital juga sangat berpengaruh terhadap fungsi motorik yang berat seperti palsi serebral, maka kerusakan otak yang terjadi cukup luas atau penyebar. Gangguan kompetensi kognitif (intelegensi) terjadi primer akibat kerusakan otak pada palsi serebral, juga sekunder akibat gangguan motorik serta kesulitan anak mengeksplorasi lingkungan yang diperlukan dalam perkembangan kognitif. Pasien palsi serebral yang dilatar belakangi kelahiran prematur, BBLR dan kesulitan perawatan lainnya akan menimbulkan hambatan interaksi visual, auditif dan takut terhadap lingkungannya, sehingga akan terjadi selain cacat fisik juga cacat sosial. Pada usia prasekolah anak palsi serebral mulai merasakan bahwa diri mereka berbeda dengan anak lain. Hal ini menimbulkan rasa takut, tidak nyaman dan ingin lepas dari lingkungan orang tua. Pada usia sekolah akan timbul rasa cemas akan kecacatannya, depresi dan pada usia remaja masalah psikososial timbul akibat kemunduran fisik, serta keterlambatan aktivitas. Pada usia dewasa, secara ekonomi sering tergantung pada orang lain dan sepertinya mereka mengalami isolasi sosial.

Kata kunci: Palsi serebral - kompetensi kognitif - aspek psikososial

$\mathcal{P}$

alsi serebral merupakan kelainan motorik yang cukup banyak dijumpai pada anak. ${ }^{1}$ Kelainan ini disebabkan oleh kerusakan otak yang menetap, tidak progresif, terjadi pada usia dini dan merintangi perkembangan otak normal. ${ }^{2}$ Istilah palsi serebral mencakup berbagai gambaran klinis, sebagai akibat rusaknya jaringan otak atau perkembangan yang abnormal pada masa pranatal

*SMF Kesehatan Anak RSUD Gianyar, Bali (Dr. Oka Lely AA), **Laboratorium/SMF Ilmu Kesehatan Anak Fakultas Kedokteran Universitas Udayana, RSUP Sanglah, Denpasar, Jl. Pulau Nias, Bali (Dr. Soetjiningsih Sp.A (K).

Alamat korespondensi:

Dr. Oka Lely AA

SMF Kesehatan Anak RSUD Gianyar, Bali.

Telpon 0361-222141/ 222142. Fax. 0361-244038/24556. natal atau pasca natal. ${ }^{3}$ Penyebab rusaknya jaringan otak yang berakibat terjadinya palsi serebral demikian banyak, dapat mengenai satu area otak yang spesifik ataupun menyebar ke seluruh korteks sampai batang otak. Berbagai gangguan dapat menyerang bersama ataupun masing-masing pada waktu yang berbeda pada berbagai fase perkembangan jaringan otak. ${ }^{4,5}$ Manifestasi klinis palsi serebral tidak terbatas pada kelainan motorik sering disertai gangguan yang lain seperti pendengaran, penglihatan (strabismus), bahkan lebih dari 50\% mereka juga menderita retardasi mental. ${ }^{6}$

Kompetensi kognitif (intelegensi) pada anak palsi serebral dapat terganggu sebagai defek primer akibat kerusakan jaringan otak ataupun sekunder akibat ketidakmampuan pasien mengeksplorasi lingkungan. ${ }^{6}$ Keberhasilan tata laksana penderita palsi serebral 
terletak pada keterlibatan keluarga mulai dari mengetahui penyebab kecacatan dan secara bersamasama merencanakan perawatan yang dibutuhkan penderita. Hambatan terjadi bila orang tua bersikap pesimis dan terlalu overprotective. Untuk mematahkan hambatan ini harus dimulai sejak awal kehidupan anak sehingga peran dokter anak sangat vital. ${ }^{7}$

\section{Perjalanan Palsi Serebral pada Anak}

Telah disebutkan di muka bahwa palsi serebral atau lumpuh otak disebabkan oleh banyak faktor yang terjadi pada masa perkembangan otak baik pranatal, natal dan pasca natal. Penyebab dari gangguan tersebut antara lain gangguan kromoson atau zat teratogenik yang terjadi pada 8 minggu pertama kehamilan yang mengganggu embriogenesis dan mengakibatkan malformasi organ yang berat. Zat teratogenik yang mengganggu sesudah trimeter I kehamilan akan mempengaruhi maturasi otak. Hipoksik iskemik dapat menyebabkan kelainan mikro anatomi, sekunder akibat migrasi neural crest dari neuron. Bila terjadi pada masa perinatal akan mengakibatkan iskemi atau perdarahan otak yang kemudian mengakibatkan infark otak. Pada masa pasca natal penyebabnya adalah infeksi, meningoensefalitis, trauma kepala, toksin dan lainnya.

Oleh berbagai sebab di atas bila yang terkena korteks motorik akan timbul kelainan yang disebut palsi serebral suatu kelainan yang ditandai dengan lambatnya perkembangan motorik, kelainan sikap tubuh atau gerakan, dan tonus otot. ${ }^{6}$

Pusat motorik di otak terletak di bagian posterior dari lobus frontalis. Di bagian anterior dari lobus frontalis terletak pusat yang mengatur kestabilan emosi dan personalitas serta tempat menyimpan ingatan baru. Lobus temporal, parietal, dan oksipital juga sangat berpengaruh terhadap fungsi motorik, selain juga untuk fungsi lainnya seperti kemampuan kognitif. Jadi bila terjadi gangguan motorik yang berat seperti palsi serebral maka bagian otak yang terkena pasti luas atau menyebar, atau dapat pula lokal, disertai oleh penyumbatan aliran pembuluh darah besar, sumbatan aliran cairan serebrospinal atau adanya aktivitas fokus epileptikus. ${ }^{8,9}$

Pada bayi gejala klinis tonus otot bervariasi, disebabkan oleh lambatnya perkembangan motorik, gangguan gerakan tubuh dan hiperefleksi. Dapat pula berbentuk hipertonik dengan sikap tubuh ekstensi dan posisi tubuh supinasi. ${ }^{6}$ Gejala ini menetap sampai umur 1-2 tahun.
Gambaran klinis palsi serebral tampaknya berubah progesif selama perkembangan anak, tetapi sebetulnya merupakan akibat perkembangan anak. Saat dia belajar bergerak, duduk, bereaksi terhadap sikap tubuh, proses itu dipandu oleh sistim sensorik dengan memberi informasi ke otak tentang keadaan abnormal fungsi tubuh baik tonus otot maupun pola gerakan. Keadaan abnormal ini yang terjadi berulang-ulang sepanjang hidup, akan memberi kesan pada otak yang menyebabkan reaksi berupa progesifnya kecacatan dengan bertambahnya umur terutama bila tak mendapat pengobatan. ${ }^{3}$

Kelainan lain yang menyertai gangguan motorik pada palsi serebral adalah tuli frekuensi tinggi, gangguan penglihatan (antara lain strabismus) maupun disleksia, kemunduran intelektual, agnosia, disfagia dan disartria. Khususnya kemunduran intelegensi (kompetensi kognitif) dapat terjadi primer mungkin akibat kerusakan otak yang juga menimbulkan palsi serebral ataupun sekunder akibat gangguan motorik dan kadang sensorik yang terjadi pada palsi serebral. Beberapa anak palsi serebral tak menunjukkan gangguan motorik yang mencolok tetapi terbukti mengalami gangguan belajar dengan kesulitan pada bidang menulis dan membaca. ${ }^{3}$

Pada palsi serebral tipe spastik yang berat, mungkin timbul reaksi gerakan abnormal bila penderita ingin bergerak, gembira, kehilangan keseimbangan, cemas atau takut dan terjadi peningkatan tonus otot. Pada pasien seperti ini sering menderita kontraktur sendi dan deformitas. Pada tipe ataksia terjadi kelambatan kontrol mata, tangan, duduk maupun berdiri. Hal ini menyebabkan kelambatan perkembangan secara umum. Anak tak mampu mempertahankan posisi tubuh atau cukup fixasi untuk menggerakkan tubuh. Pada palsi serebral tipe ataksik, juga terjadi gangguan nafas dan suara, kadang hanya timbul tangisan.

Palsi serebral tipe flasid terutama tampak pada masa bayi atau masa anak dini, sering kemudian berubah menjadi atetoid maupun spastik. Pasien ini bereaksi sangat lemah terhadap rangsangan, leher akan jatuh terkulai bila pasien diletakkan pada posisi duduk. Mereka juga mengalami kesulitan bernafas, mengunyah dan menelan makanan, bahkan sering terjadi aspirasi.

Anak palsi serebral yang menderita kebutaan akan mengembangkan sikap steriotip seperti gerakan mata, kepala, rocking, gerakan jari-jari yang mungkin disebabkan oleh penyimpangan sensorik dan hambatan emosi dalam menilai situasi yang kemudian menimbulkan stres. Pasien usia bayi yang buta, memperlihatkan gerakan mempertahankan posisi lengan abduksi sejajar dengan bahu, 
kelambatan gerakan meraih, menggenggam, memindahkan obyek dari satu tangan ke tangan lainnya.

Pada usia prasekolah (2-5 tahun) tipe dan beratnya kelainan terlihat jelas. Pada usia ini pasien hipotonik menunjukkan kelainan motorik yang berat disertai gangguan kognitif yang berat pula. Pada usia sekolah, tidak ada perkembangan motorik yang berarti. Bila mereka tidak bisa bergerak akan menimbulkan perasaan cemas ataupun hidup terasa gagal. Pada usia ini terjadi pacu tumbuh yang tinggi, terjadi peregangan otot dan ini menyebabkan spastisitas meningkat, deformitas yang lebih berat dan kesulitan bergerak.

\section{Aspek Kognitif dan Psikososial}

Kompetensi kognitif (intelegensi) dapat didefinisikan sebagai kemampuan memproses banyak informasi secara efisien dan memprogram perilaku yang menguntungkan bukan saja saat ini namun juga di kemudian hari. Dalam arti sempit kemampuan kognitif dapat disebut sebagai kemampuan untuk menyelesaikan masalah baru berdasarkan prinsip yang diketahui. ${ }^{11}$

Kemampuan kognitif berkembang sebagai hasil kerjasama dinamik antara program genetik dari perkembangan otak dan keadaan lingkungan yang dapat mempengaruhi yang meningkat selama maturasi. Seperti telah disebutkan di muka bahwa palsi serebral timbul sebagai akibat kerusakan otak atau perkembangan abnormal dari otak oleh bermacam-macam hal. Salah satu penyebabnya adalah keadaan ensefalopati yang menimbulkan kerusakan otak yang luas yang tidak saja mengenai korteks motorik tetapi juga korteks yang lain. Juga oleh adanya aberasi kromosom ataupun teratogenik akan menimbulkan kerusakan pada embriogenesis. Semua kelainan tersebut akan menyebabkan tidak berkembangnya kemampuan kognitif pada anak palsi serebral. ${ }^{6,8,9}$ Gangguan kognitif bahkan timbul pada anak palsi serebral dengan kelainan motorik yang tidak begitu mencolok seperti terlihat pada anak yang kaku (clumsy child). ${ }^{5}$

Untuk mencapai perkembangan kognitif yang normal diperlukan informasi dan rangsangan lingkungan. Pada anak palsi serebral terjadi gangguan persepsi karena ketidakmampuan anak mengeksplorasi lingkungan apalagi bila disertai gangguan penglihatan. ${ }^{3}$ Menurut Peaget (1952) dikutip dari Shepherd, ${ }^{3}$ pengalaman motorik pada awal-awal kehidupan adalah esensial bagi perkembangan kognitif. Intelegensi mungkin berkembang inadekuat jika anak tidak dapat mengekspresikan diri secara efisien. Hal ini dialami oleh anak palsi serebral yang kesulitan melakukan gerakan.

Pada minggu-minggu pertama kehidupan terjadi interaksi visual, auditif dan taktil antara bayi-ibu ataupun pengasuh, yang merupakan hal penting bagi hubungan sosial dan komunikasi bahasa selanjutnya. Pada pasien palsi serebral yang dilatarbelakangi oleh BBLR, prematur dan kesulitan perawatan lainnya yang pada umumnya respon bayi kurang terhadap lingkungan, mengakibatkan hal yang timbal balik dari ibunya. Jadi interaksi ibu-bayi akan rusak yang kemudian akan menimbulkan tidak saja cacat fisik bagi bayi juga cacat sosial. Bayi akan kehilangan pengalaman sensasi motorik yang dibutuhkan bagi perkembangan kognitif. Anak palsi serebral mungkin mengalami kelambatan maturitas emosi akibat ketergantungan yang besar terhadap orang di sekelilingnya.

Adanya anak cacat seperti palsi serebral di dalam keluarga merupakan problem tersendiri bagi orang tua. Ada rasa bersalah, rasa tak bahagia dan lainnya. Terhadap saudara pasien akan timbul rasa bingung, mungkin iri, atau permusuhan terhadap orang tua karena banyak waktu yang tersita untuk melayani saudaranya yang cacat tersebut. ${ }^{6}$ Pada usia prasekolah kemampuan kognitif anak palsi serebral mudah ditentukan karena tes yang dilakukan tidak banyak memerlukan keterampilan motorik. ${ }^{6}$ Dikatakan bahwa pada palsi serebral tipe hipotonik akan didapatkan kelainan kognitif yang berat. ${ }^{5}$

Pada usia prasekolah terjadi perkembangan persepsi pada anak. Bila anak bertemu dengan teman sebayanya yang normal mereka sudah dapat merasakan bahwa diri mereka berbeda. Ada rasa yang menakutkan, tidak nyaman, mereka ingin otonomi, sementara orang tua bertahan melindungi anak terhadap dunia luar. Pada fase ini anak mulai berfantasi yang merupakan cara bagi anak untuk mengungkapkan ekspresi diri. ${ }^{6}$ Melalui fantasi anak dapat melepaskan pikiran atau ide yang menakutkan tentang gambaran dirinya.

Pada usia sekolah mulai timbul rasa cemas akan kecacatan yang diderita dan kemungkinannya di masa yang akan datang. Awalnya mereka mengira kecatatannya bersifat sementara, tetapi dengan pikiran yang lebih matang dan melihat teman sebaya yang normal, mereka merasa bahwa cacatnya permanen. Akibatnya mereka menjadi lebih depresi bahkan timbul rasa ingin mati, ada perasaan tak berguna dan percaya mereka telah dihukum. 
Setelah memasuki masa remaja masalah psikososial ditandai dengan kemunduran status fisik, kenyataan pengobatan yang tidak disukai, terbatasnya aktivitas layaknya remaja seperti balap mobil, atletik dan keinginan seksual.

Di masa dewasa mereka umumnya bekerja di sektor yang tidak memerlukan keterampilan. Jadi secara ekonomi mereka tergantung pada orang lain. Bahkan sepertiga dari mereka mengalami apa yang disebut sebagai social isolation. ${ }^{6}$

\section{Tatalaksana}

Mengingat dampak palsi serebral pada anak tidak saja mengenai aspek fisik (motorik) tetapi juga menyangkut aspek lainnya seperti adaptif, bahasa, kognitif, pendengaran, penglihatan dan sebagainya, maka penanganannya memerlukan suatu tim yang terdiri atas berbagai kalangan profesi seperti ahli syaraf, fisioterapis, terapi okupasi, dokter anak, ahli THT, ahli mata dan lainnya dalam suatu senter tersendiri. ${ }^{3}$ Selain itu harus melibatkan orang tua pasien, mereka harus dibangun kepercayaan dirinya dalam kemampuannya merawat anaknya. Juga perlu diberi informasi dasar untuk menolong mereka memecahkan masalah secara mandiri di masa depan. ${ }^{7}$

Anak palsi serebral tipe flaksid akan mengalami masalah pernafasan, mengunyah dan menelan makanan. Oleh karena itu kepada orang tua perlu diajarkan cara melakukan postural drainage dan perkusi untuk membersihkan jalan napas. ${ }^{3}$ Anak palsi serebral yang disertai kebutaan mengalami gangguan persepsi. Terhadap mereka perlu diberikan permainan dengan menggunakan gerakan motorik kasar sedini mungkin untuk menolong perkembangan kesadaran akan posisi diri di dalam ruang, merasakan gerakan yang memberi rasa nyaman dan percaya diri. Pasien usia bayi harus dirangsang untuk meletakkan tangan di garis tengah, meraih objek dan meraba, meraih melalui arah suara, meraih objek bila dipindahkan. Mereka harus diberi kesempatan berbuat walaupun salah, sebagai bagian dari proses belajar termasuk keterampilan motorik. ${ }^{5}$

Terhadap orang tua perlu diberi informasi akan kelainan yang diderita pasien dan aspek-aspek lain yang ikut terkena. Terhadap saudara pasien, perlu ditekankan rasa menerima keadaan pasien, gambaran klinis pasien dan kemungkinan memakai alat bantu.
Pada usia sekolah saat anak mulai berfantasi sebagai cara untuk melepaskan pikiran yang menakutkan tentang gambaran dirinya, dilakukan terapi psikologis dengan latihan tingkah laku yang di dalamnya fantasi memainkan peranan penting. Dengan terapi ini anak dapat mengembangkan cara untuk mencapai penyelesaian masalah yang mereka hadapi. ${ }^{6}$ Pada usia sekolah akibat pacu tumbuh, akan terjadi keadaan spastis yang lebih berat. Mereka memerlukan koreksi operasi dan memerlukan perawatan yang lama di rumah sakit.

\section{Ringkasan}

Telah dibahas perjalanan penyakit palsi serebral serta aspek-aspek lain seperti kognitif dan psikososial yang menyertai kelainan motorik yang terjadi. Peran dokter anak sangat vital bagi keberhasilan tatalaksana pasien palsi serebral, karena biasanya merekalah yang dimintai pertolongan pertama kali oleh keluarganya. Bila mendapat penanganan pada usia dini, akan bisa menurunkan derajat kecacatan fisik maupun sosial.

\section{Daftar Pustaka}

1. Soetjiningsih. Palsi serebralis dalam tumbuh kembang anak. Penerbit Buku Kedokteran EGC, Surabaya 1995.

2. Passat, J. Kelainan perkembangan, Dalam Neurologi anak. Ikatan Dokter Anak Indonesia, Jakarta, 1999.

3. Shepherd, R.Physiotherapy in pediatrics. Penyunting: William Heinemann. Edisi kedua Medical Books Limited London, 1974.

4. Lewis M, Benderesky M. Cognitive and Motor differences among low birth weight infants : Impact of Intraventriculer hemorrhage, Medical risk and Social class. Pediatrics 1989; 83:137-92.

5. Costello DW, dkk. Perinatal correlates of cerebral palsy and other neurologic impairment among very low birth weight children. Pediatr 1998; 102:315-22.

6. Levine M, dkk. Cerebral palsy in developmental behavioral pediatrics. WB Saunders Company Philadelphia, 1983.

7. Healy A, Smith B. Cerebral Palsy: setting the stage for the future. Comtemporary Pediatrics 1988; 44-60.

8. Pollak M. Motor development. Dalam Texbook of developmental paediatrics. Churchill Livingstone Edinburgh 1993.

9. Swaiman KF. Intellectual and motor deterioration. Dalam Pediatric neurology principles and practice. Mosby Company, St Louis, 1989.

10. Lumbantobing SM. Neurologi perkembangan anak dalam anak dengan mental terbelakang. Balai Penerbit FKUI, Jakarta 1997. 